\section{Innovating Solutions to Deforestation: Cross-Sector Collaboration in the Amazon}

\author{
Hull BR *, Kimmel C, Robertson D \\ Professors, Virginia Tech, Center for Leadership in Global Sustainability, 900 North Glebe Road, Arlington, VA 22203, US
}

*Corresponding author: Robert Bruce Hull, Professor, Virginia Tech, Center for Leadership in Global Sustainability, 900 North Glebe Road, Arlington, VA 22203, US, Tel: +5718583338; E-mail: hullrb@vt.edu

Received date: January 14, 2016, Accepted date: February 22, 2016, Published date: February 28, 2016

Copyright: @ 2016 Hull RB, et al. This is an open-access article distributed under the terms of the Creative Commons Attribution License, which permits unrestricted use, distribution, and reproduction in any medium, provided the original author and source are credited.

\begin{abstract}
Global supply chains bring jobs and opportunities to developing regions but also can cause problematic impacts to businesses, governments, communities, and environments where production occurs, such as the deforestation occurring in the Amazon. Innovative strategies are being developed in response to these challenges. This case study examines how an international agriculture corporation (Cargill), collaborated with local farmers, farmers union, government agencies, and an international environmental organization (The Nature Conservancy) to innovate solutions to deforestation in Brazil caused by soybean production. Collaborators developed and delivered a program that increased soybean production and decreased deforestation. They did so by making compliance with existing laws financially feasible, easily monitored, evenly enforced, and reliably rewarded.
\end{abstract}

\section{Key words:}

Supply chain; Compliance; Soybean; Agriculture; Brazil; Sustainable development

\section{Introduction}

Global supply chains bring jobs and opportunities to developing regions but also can bring problematic consequences for businesses, governments, and communities where production occurs, such as the deforestation occurring in the Amazon as a result of expanding soybean production. Balancing the tension between environment and economy is the fundamental challenge of sustainable development. Innovative governance strategies are emerging in response to these challenges [1]. These strategies rely on collaboration among businesses, government agencies, and civil society and include concessions and licenses to manage and extract public resources, contracts between businesses and upstream landowners for provision of ecosystem services such as water, third-party certification of goods and services, commodity roundtables, and co-management of public forests or fisheries [2-4]. This paper examines one such innovation: a businessoriented strategy for promoting compliance with local regulations and best practices.

First, let us provide some context. Amazonian forests are responsible for a quarter of the world's terrestrial species, about $15 \%$ of global terrestrial photosynthesis, and evaporation that powers rain and other weather systems as far away as North America. Agriculture and other forms of development have already altered almost a million square kilometers of forests. Peak-deforestation, almost 30,000 square kilometers a year, occurred in 1995. Strategies have slowed that rate over the most recent decade, until the last few years when it shot up to an annual rate of 6,000 square kilometers.

The soybean is a multi-purpose, global commodity used for feed, food, and fuel. Brazil produced one million tons of soybeans in 1969, twenty million tons in 1989 , ninety million tons in 2014, and is now challenging the US as the world's largest producer. Much of Brazil's soy is exported to Europe and China and used as livestock feed. China began looking overseas for external food sources in the mid-1990s, when it became clear that the country's production capacity would be insufficient to meet projected demand because of limited water and land. China's soybean imports from Brazil increased nine-fold between 2000 and 2010 and are projected to increase another $40 \%$ over the next decade. Agriculture consumes about $70 \%$ of all freshwater worldwide, so the global trade in food is also a global trade in virtual wateralready China imports $14 \%$ of its water needs by its strategic decision to import soybeans from Brazil rather than grow the crop domestically $[5,6]$.

As people become wealthier, they tend to eat more meat; this trend, combined with increasing population, leads to predictions that global agricultural productivity will double in the next forty years [7]. Much of that increased production may occur in Brazil, which has more unused or underused arable land than any other country and (relatively) ample water supply [8,9]. A specific challenge for global sustainable development, then, is to increase Brazil's agricultural production while minimizing or reversing deforestation.

As explained in the case study below, Brazil has one of the most progressive forest protection laws in the world, but compliance has been inadequate, so illegal deforestation has continued. Key stakeholders in one small region of Brazil collaborated to innovate a system that would increase compliance and reduce deforestation while meeting stakeholders' interests, which includes increasing and increasingly profitable production of soybeans.

\section{Literature Review: Compliance and Innovation}

Stakeholders from different sectors have different motivations to increase compliance with local law and best practices. Businesses want to reduce uncertainty caused by arbitrary and capricious enforcement of local laws, to promote consistency with emerging international standards and norms that provide access to global markets, and to avoid controversy and negative publicity generated by actors that want 
change. Governments want the increased legitimacy and efficacy that comes with compliance with laws and regulations and to meet the long term needs of citizens. Civil society actors seek to promote their missions, such as human rights, fair labor, and maintenance of environmental commons [10-14].

The literature on compliance is diverse, but a simple four-factor model summarizes the main points. Compliance increases if each factor is achieved: feasibility, monitoring, enforcement, and reward. The factors are reviewed below and used to organize the case study that follows.

Feasibility: Practices promoting compliance must be affordable, practical, accessible, and otherwise feasible. Stakeholders need access to money, knowledge, and time to implement these practices. If costs of compliance are too high or require unattainable skills, then compliance is low. Compliance in agricultural settings tends to increase as land size, economies of scale, operational efficiencies, profitability, and related capacities increase; hence farmer assistance programs the world over focus on building these capacities [11,15-18].

Monitoring: Compliance improves when clear, practical, and affordable monitoring produces reliable and accurate assessments of compliance. Remote sensing and related technologies can reduce assessment costs, but all parties must have confidence that assessments are accurate, sensitive enough to detect meaningful transgressions, and transparent enough not to be applied capriciously [18-21].

Enforcement: Compliance increases as punishment for non compliance increases in likelihood and severity. Conversely, compliance declines with unlikely or sporadic enforcement, either due to poor resourcing of enforcement agencies, lack of political will to enforce, or lack of coordination between monitoring, regulating, and enforcement actors [12,18,21,22].

Reward: Compliance increases when the benefits of compliance are high relative to the costs. Political situations that limit penalties therefore reduce compliance, as do high costs of becoming compliant. Incentives that increase compliance include tax breaks or credits, access to capital, price premiums, and increased market share (the latter two might result from certification and labels). Compliance also increases to the extent these benefits are perceived as fairly distributed [18,23-25].

In the case described below, compliance with regulations intended to reduce deforestation had, to date, been insufficient, in part because the complex and diffuse nature of the challenge exceeded the capacity of any single stakeholder, even government. Social innovation is a strategy for addressing these sorts of challenges that are beyond the capacities of any single organization and thus require collaboration across different organizations, sectors, and places. One of the leading voices for social innovation, Stanford Graduate School of Business Social Innovation Review, defines social innovation as the process of inventing, securing support for, and implementing novel solutions to social needs and problems accomplished by dissolving boundaries and brokering a dialogue between the public, private, and nonprofit sectors [26]. Social innovation efforts are distinguished by the following attributes [26-28].

Social outcomes: Distribution of benefits is tilted toward society as a whole in addition to or in contrast to focusing only on innovation for private gain or business improvement.

Capacity Building: They leave behind compelling new social relationships between previously separate individuals and groups which contribute to the diffusion and embedding of the innovation and opens up the possibility of further innovations.

Collaborative: The ideation, testing, and pivoting process of innovation incorporates stakeholder/user needs and interests.

Cross-sector: The solution requires consideration and ideally participation of stakeholders in business, civil society, and government. Some actors and organizations are motivated by a social mission and social value creation, such as NGOs and government agencies.

Novel Combinations: Solution elements may not be new themselves but used in new combinations or hybrids of existing elements.

\section{Study Method and Background}

A case study approach was used [29]. The broad outlines of the case were constructed from information available in grey and published literature. The authors visited project sites, collected project literature, and interviewed key informants in person or by phone, including representatives from business, government, civil society organizations, and the local community (specifically, four people from TNC, four from Cargill, two from government, two farmers, and two farmers union representatives). Interviews were recorded, transcribed, and coded. TNC informants reviewed early drafts of findings for accuracy. The primary organizations involved were Cargill, an international producer and marketer of agricultural products and services; The Nature Conservancy (TNC), a leading transnational nongovernmental organization focused on environmental conservation; the State Environmental Agency of Para (SEMA); the local farmers' union; and local government agencies in Santarem, Brazil. Similar collaborative efforts began at about the same time elsewhere in Brazil: "Legal Lucas" in Mato Grosso and "Sustainable West" in Bahia [10].

Managing the impacts of producing soybeans to meet rising global demand is a daunting task that ultimately falls on local communities where soybeans grow. Santarem is a municipality located in the Brazilian state of Para. Parais in the Lower Amazon River watershed with ready access to the Atlantic, and home to world-heritage rainforests and biodiversity hotspots. Para produces at least $10 \%$ of the Brazil's livestock (Brazil is the world's leading exporter of beef), and exports increasing amounts of soy and other grains through rapidly developing ports and infrastructure. Compared to other states in Brazil, Para has among the highest concentration of indigenous lands and peoples, the most mining activity, the most timber harvesting, the most smallholder farmers, and among the lowest per capital income and highest poverty rates [30]. Understandably, the region is attracting intense interest and pressure by multinational corporations and transnational NGOs because of the opportunities and challenges emerging there. Successes achieved and lessons learned in Para will likely have wider applicability, as other regions around the world grapple with similar challenges.

Brazil has some of the most progressive environmental laws in the world that, if compliance were high, would likely address deforestation caused by producing agricultural commodities like soy. Four distinct but related government-led programs are particularly relevant to this case: (1) the Forest Code, (2) environmental licensing and registry for land owners, (3) the Federal Embargo or blacklist of non- compliant municipalities, and (4) an environmental crimes law. They are reviewed below and then we turn our attention to the challenge of innovating solutions to increase compliance with these laws and programs. 
The Forest Code, established in 1934 and revised numerous times subsequently, requires landowners to maintain forests in "Permanent Protection Areas" along water edges and in other ecologically significant areas. It also requires landowners to maintain, restore, or offset a certain percentage of forests in what are called "Legal Reserves" that cannot be farmed $80 \%$ of landholding in the Amazon region, 35\% in the Cerrado or savanna region, and $20 \%$ in other areas. The 2012 revision of the law reduced the required size of riparian buffers, and granted amnesty to owners of small parcels where forest had been cleared prior to 2008 .

Environmental Licensing is an attempt to monitor compliance with the Forest Code by differentiating between legal and illegal deforestation [14,31,32]. SLAPR is the acronym in Portuguese for "State Environmental Licensing in Rural Properties System." Each property is supposed to be mapped and farmers receive authorization to legally clear forests compliant with the Forest Code; those that clear too much are fined and required to restore the balance. Monitoring, and hence compliance, is often infeasible due to the size of the region and low-resolution of satellite imagery. Moreover, enforcement was intentionally minimal to not discourage landowners from program participation, and in recognition of the important economic and political role of agriculture in the region [14].

Two programs were created to assist land registration and licensing the Cadastro Ambiental Rural (CAR), and the Rural Registry System. The shared goal of these new programs was to establish a digital, geographic map of all privately owned rural properties by 2015 , with information about boundaries, location and amount of forest reserves, and plans to restore degraded lands, should any exist. Participating in "CAR" was (relatively) easier for landowners than the SLAPR program, and although it did not constitute an environmental license or proof of title, it constituted an important and subsidized step that landowners could take toward legal production and sale of farm produce $[33,34]$.

A third significant program, began in 2007 by a Federal Decree, required the Ministry of Environment to publish an annual list of municipalities in the Amazonia region with a high incidence of deforestation and low rates of participation in the Environmental Licensing program. The list became known as the Federal Embargo or Blacklist. Municipalities have two significant incentivizes to not be included on the list: landowners within the municipality would be denied access to credit and federal agricultural support programs, and banks would be issued a directive to not fund businesses breaking environmental laws in blacklisted municipalities.

The fourth program of significance to this case, the Environmental Crimes Law, was passed in 2009. It made agricultural producers and buyers co-responsible for environmental crimes such as violations of the Forest Code resulting from the production of soy [35]. This law was critical because it meant buyers were now liable for violations by producers.

Thus, a sophisticated legal and regulatory system was in place; yet, compliance remained inadequate and deforestation continued. In the absence of adequate compliance, local communities and environments risked being exploited to satisfy distant global markets.

\section{The Case: Innovating Compliance in Santarem}

In 2000, Cargill began constructing a port facility in Santarem that would allow soybeans and other commodities to be shipped down the Amazon river on large barges rather than transported along crowded, potholed roads in trucks that would sometimes wait days in long lines to be unloaded at Atlantic ports onto ships bound for Asia and Europe. Licensing the new port was controversial because the port was seen as the leading edge of enormous environmental and social change, including additional illegal deforestation (as of this writing at least ten new ports are in various stages of licensing, construction, and operation in Para).

The Nature Conservancy began discussions with Cargill in Sao Paulo, Brazil, and with the Cargill Foundation in the United States to develop a strategy for responding to development challenges the new port would bring to Santarem [36,37]. Because much of the soy shipped from Santarem went to a discerning European market concerned about Amazon deforestation, initial discussions held from 2004 to 2005 focused on a Forest Friendly Soy labeling system that would provide consumers the option to purchase soybeans that did not cause new deforestation. TNC and Cargill abandoned this independent effort when the Roundtable for Responsible Soy (RTRS) emerged. RTRS advocated many of the same outcomes as Forest Friendly Soy, involved many additional producers and stakeholders, and has gone on to become the world's leading soybean certification system [38,39].

TNC and Cargill supported the RTRS, but staff from both organizations had three concerns that motivated them to develop this additional strategy. Specifically, they worried that: 1) the results of RTRS would not be seen soon enough to significantly slow deforestation that was already occurring, 2) certification might not be an effective strategy in the Asian market where demand was expanding, and 3) RTRS might not be sufficient to address public concerns and scrutiny raised by Cargill's new port in Santarem. They independently pursued a "responsible sourcing" program that emphasized compliance with norms and laws such as the Forest Code. A 2006 Cargill press release explained its partnership with TNC:

"In a groundbreaking move, we have informed our suppliers and local officials that, beginning with the next crop, Cargill will only purchase soy from those producers who are in compliance with the Forest Code or actively working towards full compliance. Compliance with the Brazilian Forest Code is an important tool to reconcile agricultural production with the conservation of the Amazon forest." [40]

The literature reviewed in the introduction presents a four-factor model of compliance. When we unpacked the collaborative efforts in Santarem and examine them through the lens of compliance, we find evidence that stakeholders did, in fact, develop and deploy strategies consistent with this four - factor model. Further details about the case are organized below using the four-factor compliance model: feasibility, monitoring, enforcement, and reward.

Feasibility: Mapping and registering a property to be compliant with the Forest Code had been prohibitively expensive and technically infeasible for many producers. Moreover, becoming compliant often required removing from production lands because they are identified as ecologically sensitive, riparian buffers, and/or forest reserves. These removals threaten producer revenue by reducing land area under production. Collaborators in the Santarem case addressed these challenges by subsidizing the mapping, providing free or heavily subsidized technical assistance for restoration, and working on policy tools to establish large forest reserves in the region that could be used as offsets. They also helped arrange financing to help producers purchase those offsets as well as technological improvements to enhance farm productivity. Details of these governance mechanisms 
that make compliance feasible for producers are described in more detail in the monitoring and enforcement sections below.

Monitoring: A key obstacle to compliance was poorly defined property boundaries, poor mapping, and few tools to measure changes in forest coverage. In 2005, Cargill Foundation provided funding to TNC to build a GIS database system to map properties and monitor deforestation (this system was a precursor to CAR, the national Rural Registry Program). This transparent, accessible database that georeferenced producer and farm information allowed farmers, TNC, government agencies, producer organizations, and others to monitor what was happening on the land. Importantly, it allowed Cargill to check compliance of every load of soy they purchased in Santarem. The effort used data from 108 satellite images and 300 field visits, and covered 27,285 square kilometers [36,37]. Farmer registration in the CAR program in Para increased dramatically from 400 in 2009 to 40,000 in 2011. The goal was to have 100,000 farms registered by 2013 , representing approximately 50 percent of the farms in Para [41]. Technical capacity now exists in private consultancies and government agencies so that TNC is increasingly, and intentionally, turning over mapping and monitoring operations to local actors.

Enforcement: Enforcement of regulations had been inconsistent, not just because there was no effective monitoring, but because the Forest Code was at the center of high profile national and regional political debates and its continuation seemed dependent upon the next election. Moreover, the law's requirements had changed over time and there was discussion about creating exceptions for land previously cleared and for owners of only a few hectares (both of which did come to pass in 2012). Hence, great uncertainty existed about how compliance would be defined and enforced. Cargill resolved much of the uncertainty when it announced it would not purchase soy without proof of compliance. Since it was the major buyer for the export market, a significant number of growers responded.

Reward: Producers in Santarem were initially resistant to participate because they were being held to a higher standard than producers elsewhere in Brazil, and because there was little or no price premium for producing soybeans deemed compliant. Several incentives were created to overcome this resistance. First, Cargill committed to only purchase soy verified through this system. Second, Cargill promise to buy everything produced that was compliant, so at least growers had confidence they could sell their full harvest and generate revenues to pay for becoming compliant. Third, keeping Santarem off the national Blacklist (of Forest Code violators) allowed farmers and others to access loans and government technical assistance that otherwise would be restricted. Fourth, Cargill offered loans and technical assistance to landowners enrolled and compliant with the program. Last and most recently, Bolsa Verde do Rio de Janeiro- the Green Market of Rio helps producers with excess Legal Reserve forests sell them to producers who need to increase their reserves [42].

Social innovation, as the literature reviewed above suggests, usually emphasizes social outcomes, capacity building, cross- sector collaboration, and novel combinations of existing tools. When we unpack the collaborative efforts in Santarem and examine them through the lens of social innovation, we find evidence of these classic characteristics of social innovation. As a way to finish telling the case study, evidence for each characteristic is presented below

Social outcomes: The collaboration in Santarem produced both private and social benefits. Private benefits include those accrued by Cargill, who benefited from more and more reliable supply of high quality soybeans with traceable sourcing; and by farmers, who benefited from improved technology, loans, and market access. Social benefits were also generated. The CAR registry improved landownership accountability in the region, which was missing in the absence of a rigorous land titling system. A report from the World Bank suggested that the CAR registry was an important advancement for the state of Para [42]. The Santarem collaboration also lead to increase emphasis on improving regional transportation infrastructure. Collaborators identified poor roads, ports, and other infrastructure as a barrier making local producers less competitive (it can take weeks to import parts or export products). As a result of collaborating on soybean production, stakeholders gained a more powerful and active political voice requesting and directing regional infrastructure developments that benefited the larger community. Another obvious social benefit was reduced deforestation.

Capacity Building: The Santarem collaboration built capacity to address other pressing issues in the region, including professional services and better governance. The region lacked professionals who could provide technical environmental services, hence limiting other regional sustainable development opportunities. TNC intentionally trained local people and turned monitoring and mapping operations over to them. As a result, a workforce for property surveying, GIS mapping, logistics, and remote sensing was developed. Government capacity to engage and promote sustainable development also increased. The State of Para established a Green Municipalities Program in March 2011 (Para State Decree 54) that mirrored some of the goals of the soybean collaborative. It created a land-use zoning tool to direct development to where it can be most productive economically and least damaging environmentally. In addition, it introduced environmental education into public schools. The Santarem collaboration also built capacity within TNC: lessons learned in Santarem would be transferred elsewhere.

"Santarem was our school...When we started here, we didn't even have an idea of what to do. This wasn't about conservation in books. We developed a strategy after we got here. Now, we think we have a model that will work for the entire Amazon-and that may be the biggest contribution of the Sustainable Soy project" [37].

Cross-sector and Collaborative: Certainly, the effort was collaborative: the results could not have been accomplished without significant contributions by all stakeholders. Moreover, the collaboration involved stakeholders from multiple sectors: farmers, farmers unions, Cargill, TNC, community groups, and numerous government agencies.

Novel Combinations: The compliance strategy did not require inventing a completely new solution, but rather tweaking and combining existing technologies, roles, and programs into a new combination to address the standing problem of noncompliance. For example, the Forest Code already provided a government mandate, GIS and property survey technology already existed, and Cargill already had a form of product source certification to distinguish between GMO and non-GMO crops destined for Europe. The innovation that occurred was that of enhancing and recombining these existing capacities into a new system that addressed soybean- caused deforestation.

\section{Conclusion}

Global supply chains bring jobs and opportunities to developing regions but also can cause problematic impacts to businesses, 
governments, and communities where production occurs, such as deforestation in the Amazon driven by soybean production. Innovative governance such as cross-sector collaboration to promote compliance with existing regulations and best practices provides one solution. The result of the collaboration among cross -sector actors in Santarem Brazil has the potential to sustain and likely increase legal soy production and reduce rates of illegal deforestation. Collaborators worked to create conditions that made it more feasible for farmers to become compliant by developing and applying a reliable and accurate monitoring system, by increasing enforcement capacity, and by increasing rewards for being compliant. In conclusion, we learned from this case study how collaboration among NGO, business, and government actors can develop an innovative solution out of existing capacities to address a complex sustainable development challenge, in this case, illegal deforestation driven by global demand of agricultural products.

\section{Acknowledgment}

We would like to acknowledgement Christoph Hrdina for the doors he opened and interviews he translated, to Edenise Garcia with TNC for fact checking, and the interviewees at Cargill, The Farmer's Union of Santarem, and TNC- Amazon program headquartered in Belem.

\section{References}

1. Young OR (2013) On environmental governance: Sustainability, efficiency, and equity.

2. Armitage D, de Loe R, Plummer R (2012) Environmental governance and its implications for conservation practice. Conservation Letters 5: 245-255.

3. Delmas MA, Young OR (2009) Governance for the environment: New perspectives. Cambridge University Press.

4. Head BW (2008) Assessing network-based collaborations. Public Management Review 10: 733-749.

5. Dalina C, Konara M, Hanasakib N, Rinaldoc A, Rodriguez-Iturbea I, et al. (2012) Evolution of the global virtual water trade network 109: 5989-5994.

6. Brown-Lima C, Cooney M, Cleary D (2011) An overview of the brazilchina soybean trade and its strategic implications for conservation. The Nature Conservancy Latin America Region.

7. Searchinger T, Hanson C, Ranganathan J, Lipinski B, Waite R, et al. (2014) Creating a sustainable food future. A menu of solutions to sustainably feed more than 9 billion people by 2050 . World resources report 2013-14: Interim findings.

8. Boucher D, Elias P, Lininger K, May-Tobin C, Roquemore S, et al. (2011) The root of the problem what is driving deforestation today? Union of Concerned Scientists.

9. Rada N (2013) Assessing brazil's cerrado agricultural miracle. Food Policy 38: 146-155.

10. Brannstrom C, Rausch L, Brown JC, de Andrade RMT, Miccolis A, et al. (2012) Compliance and market exclusion in brazilian agriculture analysis and implications for "soft" governance. Land use policy 29: 357-366.

11. Gunningham N (2011) Enforcing environmental regulation. Journal of environmental law 23: 169-201.

12. Heyes A (2000) Implementing environmental regulation: Enforcement and compliance. Journal of Regulatory Economics 17: 107-129.

13. Lai LWC, Yung P, Li RYM, Ho DCW (2007) The private supply of and public demand for planning: Compliance with planning conditions in the absence of direct statutory enforcement measures. Planning, Practice and Research 22: 535-557.

14. Rajao R, Azevedo A, Stabile MC (2012) Institutional subversion and deforestation: Learning lessons from the system for the environmental licensing of rural properties in mato grosso. Public Administration and Development 32: 229-244.

15. Etiegni C, Ostrovskaya E, Leentvaar J, Eizinga F (2011) Mitigation of illegal fishing activities: Enhancing compliance with fisheries regulation in lake victoria (kenya). Regional Environmental Change 11: 323-334.

16. Garrett RD, Lambin EF, Naylor RL (2013) The new economic geography of land use change: Supply chain configurations and land use in the brazilian amazon. Land Use Policy 34: 265-275.

17. Stafford S (2012) Do carrots work? Examining the effectiveness of EPA's compliance assistance program. Journal of Policy Analysis and Management 31: 533-555.

18. Stickler CM, Nepstad DC, Azevedo AA, McGrath DG (2013) Defending public interests in private lands: Compliance, costs and potential environmental consequences of the brazilian forest code in mato grosso. Philosophical Transactions of the Royal Society B: Biological Sciences 368: 20120160.

19. Fortmann L, Cordero P, Sohngen B, Roe B(2014) Incentive contracts for environmental services and their potential in redd.

20. Purdy R (2010) Using earth observation technologies for better regulatory compliance and enforcement of environmental laws. Journal of environmental law 22: 59-87.

21. Prior A (2000) Problems in the theory and practice of planning enforcement. Planning Theory and Practice 1: 53-69.

22. Gray WB, Shimshack JP (2011) The effectiveness of environmental monitoring and enforcement: A review of the empirical evidence. Review of Environmental Economics and Policy 5: 3-24.

23. Clarke P, Jupiter SD (2010) Law, custom and community-based natural resource management in kubulau district (Fiji). Environmental Conservation 37: 98-106.

24. Hansen CP (2011) Forest law compliance and enforcement: The case of on-farm timber extraction in ghana. Journal of Environmental Management 92: 575-586.

25. Yano Y, Blandford D (2009) Use of compliance rewards in agrienvironmental schemes. Journal of agricultural economics 60: 530-545.

26. Phills JA, Deiglmeier K, Miller DT (2008) Rediscovering social innovation. Stanford Social Innovation Review pp : 35-43.

27. Kelly T (2001) The art of innovation.

28. Bason C (2010) Leading public sector innovation: Co-creating for a better society. Policy Press.

29. Yin RK (2002) Case study research design and methods.

30. Nepstad D (2009) The end of deforestation in the brazilian amazon pp: 1350-1351.

31. Fearnside P, Figueiredo AMR, Bonjour SCM (2013) Amazonian forest loss and the long reach of china's influence. Environment Development and Sustainability 15: 325-338.

32. Fearnside PM (2003) Deforestation control in mato grosso: A new model for slowing the loss of brazil's amazon forest. AMBIO: A Journal of the Human Environment 32: 343-345.

33. Macedo MN, DeFries RS, Morton DC, Stickler CM (2012) Decoupling of deforestation and soy production in the southern amazon during the late 2000s. Proceedings of the National Academy of Sciences 109: 1341-1346.

34. Patriota A (2009) Rainforests and regulation: New directions in brazilian environmental law and legal institutions: An introduction to brazilian environmental law. Geo Wash Int'l L Rev 40: 611-1375.

35. Cleary D (2007) Responsible soy in the amazon the nature conservancy amazon conservation program.

36. Dienhart P (2010) Amazon report a conservation success.

37. Hospes O, van der Valk O, Mheen-Sluijer J (2012) Parallel development of five partnerships to promote sustainable soy in brazil: Solution or part of wicked problems. International Food and Agribusiness Management Review pp: 15.

38. Schouten G, Leroy P, Glasbergen P (2012) On the deliberative capacity of private multi-stakeholder governance: The roundtables on responsible soy and sustainable palm oil. Ecological Economics 83: 42-50. 
Citation: Hull RB, Kimmel C, Robertson D (2016) Innovating Solutions to Deforestation: Cross-Sector Collaboration in the Amazon. J Entrepren Organiz Manag 5: 172. doi:10.4172/2169-026X.1000172

Page 6 of 6

39. Amazonia (2006) Cargill's view on the greenpeace report: Eating up the amazon.

40. Butler RA (2020) Brazil can eliminate deforestation by 2020, say governor of giant amazon state.
41. Barbassa J (2013) Bvrio allows brazil's growers to sell 'quotas' to farmers.

42. Bank W (2010) Brazil - rural environmental cadastre technical assistance project. 